15. Population, age and sex distribution, Cape Town 2003. http://www.capetown.gov.za/clusters/health (accessed 24 June 2006).

6. Emby DJ, Hunter M. The value of ultrasound in the HIV-infected patient with a fever of undetermined origin. S Afr Med J 2002;92(8):566.

17. Hudson CP, Wood R. Ultrasound for the diagnosis of HIV-associated tuberculosis. S Afr Med J 2003;93(6):440-441.

18. Meintijes GA. Delay in the diagnosis of TB. Poster presentation at the South Africa AIDS Conference, Durban, August 2003.

19. Wilson D, Nachega J, Morroni C, Chaisson R, Maartens G. Diagnosing smear-negative tuberculosis using case definitions and treatment response in HIV-infected adults. Int J Tuberc Lung Dis 2006;10(1):31-38.

20. Hudson CP, Wood R, Maartens G. Diagnosing HIV-associated tuberculosis: reducing costs and diagnostic delay. Int J Tuberc Lung Dis 2000;4(3):240-245.

21. Reuter H, Burgess LJ, Doubell AF. Role of chest radiography in diagnosing patients with tuberculous pericarditis. Cardiovasc J S Afr 2005;16(2):108-111.
22. Ortona L, Federico G. Pulmonary and extrapulmonary tuberculosis. Rays 1998;23(1):64-77.

23. Raviglione MC, Narain JP, Kochi A. HIV-associated tuberculosis in developing countries: clinical features,

24. Uzunkov A, Harma M. Harma M. Diagnosis of abdominal tuberculosis: experience from 11 cases and review of the literature. World J Gastroenterol 2004;10(24):3647-3649.

25. Mukadi YD, Maher D, Harries A. Tuberculosis case fatality rates in high prevalence populations in sub-Saharan Africa. AIDS 2001;15(2):143-152.

26. Pitchenik AE, Fertel D, Bloch AB. Mycobacterial disease: epidemiology, diagnosis, treatment, and prevention. Clin Chest Med 1988;9(3):425-441.

\title{
Postgraduate palliative care education: Evaluation of a South African programme
}

\author{
Carla D L Ens, Harvey Max Chochinov, Elizabeth Gwyther, Stephen Moses, Catherine Jackson, Genevieve Thompson, \\ Richard Harding
}

Aim. We aimed to assess the postgraduate palliative care distance education programme of the University of Cape Town (UCT) in terms of its perceived ability to influence palliative care delivery.

Methods. A mixed-methods approach, consisting of two surveys using open-ended and multiple-choice options, was conducted from January to December 2007 at the UCT School of Public Health and Family Medicine. All students registered in the programme from 2000 - 2007 were invited to participate; 83 (66.4\% of all eligible participants) completed the general survey, and $41(65.7 \%)$ of the programme's graduates completed the graduate survey. The survey scores and open-ended data were triangulated to evaluate UCT's palliative care postgraduate programme.
Results. General survey scores of graduates were significantly higher in 5 of the 6 categories in comparison with current students. The graduate survey indicated that curriculum and teaching strengths were in communication and dealing with challenging encounters. Graduates also stressed the need to develop a curriculum that incorporated a practical component.

Conclusions. In addition to current postgraduate training, palliative care education in South Africa should be extended to undergraduate medical students, as the benefits of UCT's programme were limited to a small cohort of practitioners.

S Afr Med J 2011; 101: 42-44
Faculty of Medicine, Department of Community Health Sciences, University of Manitoba, and Manitoba FASD Centre

Carla D L Ens, PhD

Manitoba Palliative Care Research Unit, and Department of Psychiatry, University of Manitoba

Harvey Max Chochinov, MD, PhD, FRSC

Centre for Global Public Health, Department of Community Health Sciences, University of Manitoba

Stephen Moses, MD, MPH

Faculty of Nursing, University of Manitoba Genevieve Thompson, $\mathrm{PhD}$

School of Public Health and Family Medicine, University of Cape Town Elizabeth Gwyther, MB ChB, FCFP (SA), MSc Pall Med

Catherine Jackson, BSocSci, BA (Hons)

Department of Palliative Care, Policy \& Rehabilitation, King's College London, and School of Medicine at Guy's, King's and St Thomas Hospitals Richard Harding, $\mathrm{PhD}$
Palliative care improves care for people throughout the course of progressive incurable illness. There has been a worldwide effort to increase and improve palliative care education. The World Health Organization (WHO) challenged training institutions to ensure that palliative care was compulsory and given high recognition. ${ }^{1}$ Education programmes in training institutions have found palliative care programming to be patchy or non-existent in developed ${ }^{2-6}$ and developing nations. ${ }^{78}$ As palliative care is in its infancy in South Africa, medical schools are only beginning to teach it now at undergraduate level, and do not offer postgraduate palliative care programmes.

In response to this lack of educational offerings, UCT began a postgraduate distance palliative care education programme for doctors in 2000. The programme, designed to be completed in 2 - 3 years, offers a diploma and a master's of philosophy degree. Assignments are e-mailed to students and, in their first 2 years, students also attend a 3-day face-to-face instruction workshop. Master's students complete a research study. ${ }^{9}$

Programme planners and conveners believe that the programme has enhanced graduates' abilities to attend to palliative and end-oflife care issues. However, a formal evaluation was needed to assess its effect on the health care practices of course participants and the wider community. In the context of a larger descriptive study, we 
asked current and former students: $(i)$ what are/were the positive and negative aspects of the programme? and (ii) how they evaluated the influence on their medical practice of their educational experience provided through the programme.

\section{Methods}

The study was conducted from January to December 2007. Ethical approval was given by UCT, the University of Manitoba, and the Hospice and Palliative Care Association of South Africa. All programme registrants from 2000 to $2007(N=134)$ were accessed through UCT's School of Public Health and Family Medicine; contact information was available for 125 registrants. Packages containing consent forms and surveys were mailed between February and June 2007. Two reminders were sent via e-mail or regular post to nonresponders. A total of 85 students and graduates participated.

The general survey comprised 31 questions to evaluate student competence in five areas: (i) palliative care activities; (ii) pain; (iii) assessment; (iv) changes in management protocols; and $(v)$ general palliative care concepts. Scores could range from 0 to 93 points; a higher score indicated the perception of greater competence. Choices ranged from 0 (Needs further basic instruction or extremely incompetent) to 3 (Can perform independently or extremely competent). The graduate survey included 25 multiple-choice questions $(0-100$ points) and 8 open-ended questions soliciting qualitative data. Both instruments were field-tested in South Africa before use.

The survey data were analysed using SPSS 11.0. To identify and address any potential outliers, frequency distributions were examined. Non-parametric tests were conducted to assess whether significant differences existed between groupings. ${ }^{10}$ A level of significance of $p<0.05$ was chosen. Qualitative data were analysed using thematic content analysis. ${ }^{11}$

\section{Results \\ General survey}

Of the 125 eligible participants, $83(66.4 \%)$ completed the general survey, which was completed by current students (44) and graduates (39); women comprised 47 (56.6\%).

Cronbach's alpha for the survey items was 0.81 . The highest average score per question (indicating that participants perceived themselves to be able to perform a task independently or with extreme competence) was in Palliative Care Activities (2.78 out of 3 , SD 0.43), where questions pertained to family conferences, giving bad news, the palliative care treatment approach, home-based hospice referrals, and treatment withdrawal. The lowest average score was in General Concepts in Palliative Care (2.17, SD 0.50), which included paediatric palliative care, cultural issues in dealing with death and dying, patient and staff communication, teamwork, knowing how to access local palliative care resources, and the broader public policy debate around palliative care in South Africa.

Comparing graduates with students showed that, in total score and category scores, the graduates scored higher (total score: current students - mean 71.4, SD 14.2, graduates - mean 79.0, SD 9.9). Graduates had significantly higher scores than current students in all categories, with $p$-values ranging from $0.011-0.050$, with the exception of General Palliative Care Concepts, where the difference was minimal $(p=0.054)$.

Comparing responses by programme level (first year, second year, continuing students and graduates) indicated significant differences: Activity $\left(\chi^{2(3)}=27.36, p<0.01\right)$; Pain $\left(\chi^{2(3)}=14.93, p<0.01\right)$; Assessment and Management $\left(\chi^{2(3)}=13.72, p<0.01\right)$; General Palliative Care Concepts $\left.\left(\chi^{2(3)}\right)=15.16, p<0.01\right)$; Changes in Treatment $\left(\chi^{2(3)}=23.85\right.$, $p<0.01)$; and Overall Score $\left(\chi^{2(3)}=21.31, p<0.01\right)$. These significant findings were further explored by pair-wise Mann-Whitney post hoc comparisons. In all categories, the scores of first-year students were significantly lower than those of second-year students, continuing students and graduates (range $p=0.028-<0.01$ ). In the two categories Changes in Treatment and Overall Score, second-year students had significantly lower scores than continuing students and graduates ( $p$-values $0.049-<0.01$ ). Consequently, students' perception of confidence and competence increased over time.

\section{Graduate survey}

Results indicated that the average length of time it took respondents to complete the programme was 1.8 years (range $1-5$ years, median 1 year). Women comprised 27 (65.9\%) of respondents.

With the graduate survey, higher scores indicated a perception that the programme was helpful or useful. Responses were considered as continuous variables and were coded as 0 (not applicable), 1 (no opinion), 2 (not helpful), 3 (somewhat helpful), and 4 (very helpful). The highest average category scores were in General Aspects, which included topics pertaining to management of patients with different conditions, therapeutic principles and practices, knowledge of various treatment choices, and pain management (3.77, SD 0.29). The lowest average category scores were in End of Life Care in South Africa, which examined topics such as the collaboration between public health care structures and non-governmental organisations, the public policy debate, and local facilities for palliative care (3.08, SD 0.70).

Two themes (Progressive Influence of the Palliative Care Course, and Room for Improvement) best summarised participants' qualitative responses.

The Progressive Influence of the Palliative Care Course. From changes that occurred on an individual level, to systemic changes in the larger health care environment, respondents emphasised how the programme had progressively altered their understanding of medical care for persons with life-limiting illness, which spread into different facets of their professional lives. The course material appeared to affect different areas of the health care system in which students worked.

Room for Improvement. Asked to identify any weaknesses in the UCT programme, to provide feedback for future programme planning, a higher proportion of respondents either reported that there were no apparent weaknesses $(N=7,17 \%)$ or left this section blank $(N=3,7.3 \%)$; $31(75.6 \%)$ of the respondents identified areas that they wished had been included in the curriculum. A notable deficit perceived in the course was that there was no practical component. Although the course was presented via distance education, respondents felt that a practical evaluated clinical rotation with hands-on experience was necessary.

\section{Discussion}

The postgraduate programme was highly regarded by participants, and most perceived the programme and their experiences as furthering their palliative care knowledge. The qualitative data and the surveys identified significant, positive progression over time in respondents' knowledge and confidence in providing palliative care. The results of the Graduate Survey gave insight into the strengths and weaknesses of the programme and will inform future programme development.

\section{Incorporating a practical component to extend theoretical learning}

Graduates identified that a hospice rotation, at minimum, should be a requirement to benefit from hands-on experience. It may be more difficult to incorporate experiential learning or interdisciplinary teams within a distance education programme design. However, the 
benefits may outweigh the challenges as the programme does not incorporate patient contact. The literature underscores that applying theory in a practical setting is vital to higher learning. ${ }^{12}$ Active learning could be provided if distance education students worked as part of an interdisciplinary team within a palliative care setting, and directly with patients and family members. ${ }^{13}$

\section{Undergraduate education}

The programme was an elective postgraduate offering in which only the doctors who chose to further their studies in the field received specialised training in palliative care. Owing to the increasing burden of illness in South Africa, palliative care training must be provided to all medical students. ${ }^{14}$ An increase in the palliative care content of undergraduate and postgraduate training, and the inclusion of compulsory palliative care curricula within medical education, is in keeping with the WHO guidelines, which stress professional education. ${ }^{15}$

Globally, palliative care is increasingly being incorporated into medical schools in a more deliberate fashion ${ }^{2,17}$ and viewed as a critical curriculum element. South African universities should strive towards this end. A commitment to palliative care education must be made to continue to improve patients' quality of life.

\section{Limitations}

The self-report methods used can only measure the perception of change and are limited in fully understanding behavioural change. ${ }^{18}$ Doctors reporting on their own care provision could introduce bias: the desire to report a positive effect might have led to overly favourable responses; difficulty in recalling details when asked to reflect on past experiences might have led to misrepresentations of experiences. As no other measurement was administered (e.g. chart audit) to determine whether the reported changes in care practice were observed in daily routine or whether inconsistencies existed, this study might have contained an element of subjective bias. Also, non-response bias may mean that those with smaller gains and higher dissatisfaction might not have responded to the questionnaires.

\section{Conclusion}

Examples of educational assessment in postgraduate medical education are scarce, with little evidence describing effective educational assessment and how palliative care education influences practice. Evaluation is important in the development of a successful palliative care educational programmes; feedback from evaluation assists in keeping an intervention current, applicable to current community needs, and appropriate for participants. Our study may help to improve the status of palliative care education in South Africa by incorporating evidence to improve current education programming and practice. Palliative and hospice care no doubt will evolve into a mainstream service within South Africa's health care system.

This work was carried out with the aid of a grant from the International Development Research Centre, Ottawa, Canada www.idrc.ca. Additional funding was provided by the Social Sciences and Humanities Research Council of Canada, the Manitoba Palliative Care Research Unit, and the Manitoba Health Research Council. We thank the participants who gave of their time to this research and UCT for hosting the primary investigator during the project. There were no competing or conflicting interests.

\section{References}

1. Scott JF, MacDonald N, Mount BM. Palliative medicine education. In: Doyle D, Hanks WC, MacDonald N, eds. 2nd ed. Oxford Textbook of Palliative Medicine. Oxford: Oxford Medical Publications, 1998: N, eds. 2 nd

2. Lloyd-Williams M, Carter YH. Can medical education extend palliative care? Palliat Med 2003; 17(7); $640-642$.

3. Kelley ML, Habjan S, Aegard J. Building capacity to provide palliative care in rural and remote communities: does education make a difference? J Palliat Care 2004; 20(4): 308-315.

4. Cairns W, Yates PM. Education and training in palliative care. Med J Aust 2003; 179(6 Suppl): S26-28. 5. Aulino F, Foley K. Professional education in end-of-life care: a US perspective. J R Soc Med 2001; 94(9): 472-476; discussion 477-478.

6. Lloyd-Williams M, MacLeod R. A systematic review of teaching and learning in palliative care within the medical undergraduate curriculum. Med Teach 2004; 26(8): 683-690.

7. Krasuska ME, Stanislawek A, Mazurkiewicz M. Palliative care professional education in the new millennium: global perspectives--universal needs. Ann Univ Mariae Curie Sklodowska [Med]. 2002; 57(1): 439-443.

8. Bateman C. Academics break rural health ground. S Afr Med J 2002; 92(10): 754-755.

9. Gwyther E. Programmes in Palliative Medicine. 2004.

10. Norusis MJ. SPSS 10.0 guide to data analysis. Upper Saddle River, NJ: Prentice Hall, 2000.

11. Shank GD. Qualitative research: a personal skills approach. Upper Saddle River, NJ: Pearson Education, 2002.

Education, 2002. 2. Low J, Cloherty M, Wilkinson S, Barclay S, Hibble A. A UK-wide postal survey to eva
care education amongst General Practice Registrars. Palliat Med 2006; 20(4): 463-469.

13. Hall P, Hupe D, Scott J. Palliative care education for community-based family physicians: the development of a program, the evaluation, and its consequences. J Palliat Care 1998; 14(3): 69-74.

14. Bradshaw D, Groenewald P, Laubscher R, et al. Initial burden of disease estimates for South Africa, 2000. S Afr Med J 2003; 93(9): 682-688.

15. World Health Organization. A Community Health Approach to Palliative Care for HIV/AIDS and Cancer Patients. Geneva: World Health Organization, 2007.

16. Kellehear A. Health Promoting Palliative Care. New York: Oxford University Press, 1999.

17. Weissman DE, Blust L. Education in palliative care. Clin Geriatr Med 2005; 21(1): 165-175, ix.

18. Fischer SM, Gozansky WS, Kutner IS, Chomiak A, Kramer A. Palliative care education: an intervention to improve medical residents' knowledge and attitudes. J Palliat Med 2003; 6(3): 391-399. 